\title{
The Big Crunch
}

\section{David Goodstein}

The following article is an edited version of a plenary lecture given at Pittcon in New Orleans on March 8, 1995. Previous versions of this article have been published as "Scientific Ph.D. Problems," American Scholar, 62 (1993), and "Scientific Elites and Scientific Illiterates," Ethics, Values and the Promise of Science, Forum Proceedings, Sigma Xi, The Science Research Society (February 25-26, 1993) p. 61, and Engineering and Science 56 (Spring 1993) p. 22. David Goodstein is vice provost, professor of physics and applied physics, and the Frank J. Gilloon Distinguished Teaching and Service Professor at the California Institute of Technology.

According to modern cosmology, the Universe began about 10 billion years ago with the Big Bang. It has been expanding ever since. If the density of matter in the Universe is sufficiently large, gravitational forces will eventually cause the Universe to stop expanding, and then to start falling back in upon itself. If that happens, the Universe will end in a second cataclysmic event that cosmologists call the Big Crunch.

A vaguely similar theory applies to the profession, or business, of science. The scientific enterprise, which exploded into being around the year 1700 , began to run into the limits of growth around the year 1970. Exponential expansion is now in the process of ending, not really in a Big Crunch, but in something much more like a whimper. In the meantime, we are still trying to maintain a social structure of science-research, education, institutions, funding, and so on-that is based on the unexamined assumption that the future will be like the past. Since I believe that to be impossible, I think we have some interesting times ahead of us.

The situation is illustrated by the graph in Figure 1 by Derek da Solla Price. It is a plot, on a semilogarithmic scale, of the cumulative number of scientific journals founded world-wide on the vertical scale, versus time in years on the horizontal. A straight line with positive slope on this kind of graph means pure exponential growth. It shows that science seemed to spring into being around 1700 , and it expanded exponentially, growing about a factor of 10 every 50 years, until about 1950.

Price correctly predicted that this behavior could not go on forever. The straight line in the plot extrapolates to one million journals by the millennium. Instead, the current number of scientific journals is a mere 40,000 .

The era of exponential growth in science is already over. The number of journals is only one measure. Another is the number of PhD degrees in physics produced each year in the United States. The graph in Figure 1 shows that the first PhD degree was awarded soon after the Civil War, around 1870 . By the turn of the century the number was about 10 per year; by 1930 about 100 per year; and by 1970 , 1,000 per year. The curve extrapolates to about 10,000 a year today, and one million a year in 2050. But the growth stopped cold around 1970, and the number has fluctuated around 1,000 per year ever since. In physics, the Big Crunch happened around 1970. In other scientific fields, the timing may be a bit different, but the basic phenomenon is inevitable.

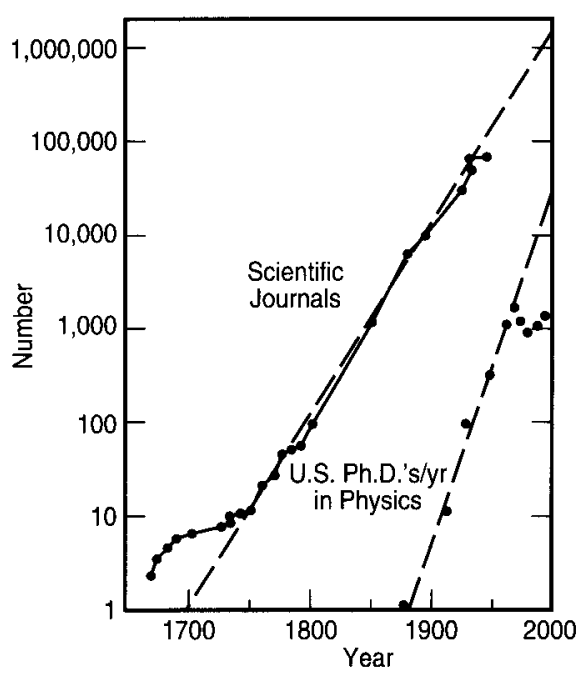

Figure 1. The upper curve was first published in historian Derek da Solla Price's book, Science Since Babylon (Yale University Press, New Haven, 1961). The lower curve is based on data from the American Physical Society, the National Academy of Sciences, and other sources. As explained in the text, both curves illustrate the long era of exponential expansion of science.
The period 1950-1970 was the Golden Age of science in the United States. There was a proliferation of science PhD students, whose research led to the founding of journals, to the acquisition of prizes and awards, and to increases in every other measure of the size and quality of science. At the same time, U.S. corporations such as AT\&T, IBM, and others created or expanded their central research laboratories to solve technological problems, and also to pursue basic research that would provide ideas for future developments. The federal government established a network of national laboratories that also became a source of jobs and opportunities for aspiring scientists. And, in 1957, the Soviets gave expansion another boost by launching Sputnik and convincing us we weren't producing enough scientists and engineers.

During the past 20 years exponential growth had ended, but federal funding of scientific research, in inflation-corrected dollars, still doubled, and the number of academic researchers had also doubled. The fraction of the best U.S. students who decided to go to graduate school started to decline around 1970, and it has been declining ever since, but the Golden Age of academic science produced excellence in our universities that attracted students from all over the world. Over the past 20 years the missing American graduate students have been replaced by foreign students. In addition, these years have seen the burgeoning of postdoctoral research positions, a kind of holding tank for scientific talent that allows young researchers to delay confronting reality for three or six years or more. These are the changes that have permitted U.S. research universities to pretend that nothing changed when the Big Crunch came 25 years ago.

The real crisis coming has started to produce a number of symptoms, some alarming and some merely curious. One of these is what I call the Paradox of Scientific Elites and Scientific Illiterates. As a lingering result of the Golden Age, we still have the finest scientists in the world in the United States, but we also have the worst science education in the industrialized world. Students in the nation's schools consistently rank at the bottom of all those from advanced nations in tests of scientific knowledge, and furthermore, roughly $95 \%$ of the U.S. public is consistently found to be scientifically illiterate.

U.S. science education is like a mining and sorting operation, designed to cast aside most of the mass of common human debris, but at the same time to discover 
and rescue diamonds in the rough that are capable of being cleaned and cut and polished into glittering gems just like us, the existing scientists. This analogy accounts for exponential growth, since it takes scientists to identify prospective scientists. It explains why women and minorities are woefully underrepresented among scientists, because we white, male scientists have difficulty perceiving that those students, cleaned, cut and polished, will look like us. It also resolves the Paradox of Scientific Elites and Scientific Illiterates. The United States has the best scientists and the most poorly educated students in the world because that is what the system of science education is designed to produce.

To most of us who are professors, finding gems to polish is not our principal problem. Exponential growth has necessarily ceased, but we have pretended that it only paused. We've continued to turn out PhD students, and the solution of the present-day leaders of science to the problem of excess $\mathrm{PhD}$ production is to advise our $\mathrm{PhD}$ graduates on alternative careers they might pursue after getting the degree, other than doing scientific research, which is what we train them to do. Why they need that training to do something else is not discussed.

The crises that face science are not limited to jobs and research funds. Under stress from those problems, other parts of the scientific enterprise have started showing signs of coming unglued. One of the most essential is the matter of honesty and ethical behavior among scientists.

In recent years an increasing number of cases of fraud has been committed by sci- entists, undoubtedly because the perpetrators have felt themselves under intense pressure to compete for scarce resources, even by cheating if necessary. Peer review is another practice becoming increasingly dysfunctional as referees take advantage of their privileged anonymity to advance their own interests.

For science to survive, we must find a radically different social structure to organize research and education in science after the Big Crunch. The new structure will come about by evolution rather than design because, for one thing, neither I nor anyone else has the faintest idea of what it will turn out to be, and for another, even if we did know where we are going to end up, we scientists have never been very good at guiding our own destiny. Only this much is sure: The era of exponential expansion will be replaced by an era of constraint. Because it will be unplanned, the transition is likely to be messy and painful for the participants. In fact, as we have seen, it already is. Ignoring the pain for the moment, however, I would like to look ahead and speculate on some conditions that must be met if science is to have a future as well as a past.

Two essential and clearly linked conditions must be considered. One, we must have a broad political consensus that pure research in basic science is a common

Material Matters is a forum for expressing personal points of view on issues of interest to the materials community. good that must be supported from the public purse. The second is that the mining and sorting operation described must be discarded and replaced by genuine education in science, not just for the scientific elite, but for all U.S. citizens who must form that broad political consensus.

Basic research is a common good for two reasons: It helps to satisfy the human need to understand the universe we inhabit, and it makes new technologies possible. Because basic research in science flourishes only when it is fully open to the normal processes of scientific debate and challenge, the results must be available to all. Thus, it must be supported from the public purse because it does not yield profits if it is supported privately. Not everyone wants to be a scientist. It follows that in order to serve the need of satisfying human curiosity, we scientists must find a way to teach science to nonscientists. One possibility is for our excess of PhD students in science to teach in high schools, but first the financial status and prestige of high school teachers would have to change dramatically.

Today's scientific leaders in the universities, government, industry, and the scientific societies are mostly people who came of age during the Golden Age. We think those were normal times and expect them to return. However, it is by no means certain that science will even survive, much less flourish, in the difficult times we face. Before it can survive, those of us who have gained so much from the era of scientific elites and scientific illiterates must learn to face reality, and admit that those days are gone. I think we have our work cut out for us.

\section{Career Activities at the 1995 Materials Research Society Fall Meeting}

\section{CAREER SERVICES CENTER}

Tuesday, Nov. 28-Thursday, Nov. 30 from 8:00-5:00 pm

Cape Cod Room in the Boston Marriott/Copley Place,

110 Huntington Avenue, Boston, MA 02116

Preregistration Monday, November 27 from 5:00-7:00 pm, outside the Cape Cod Room.

The Career Services Center is free of charge to MRS members and fall meeting registrants seeking employment. Employers interviewing for open positions will be charged a modest fee and given a discount for pre-registering before November 17, 1995. Operated by the American Institute of Physics (AIP).

\section{CAREER WORKSHOP}

Sunday, November 26, 1995 from 2:00-5:00 pm

Salon E in the Boston Marriott/Copley Place,

110 Huntington Avenue, Boston, MA 02116

The Career Workshop provides insight on career choices in MS\&E. Topics include Job Prospects:

Present and Future, How to Present Oneself in a Resume, Traditional and Diverse Positions for Physicists, Interviewing and Networking to Uncover Employment, and federal funding resources. Program assistance furnished by MRS University Chapter of University of Rochester.

\section{For more information, contact the AIP Career Services Division,$$
\text { One Physics Ellipse, College Park, MD 20740; }
$$$$
\text { phone 301-209-3190; fax 301-209-0841; or e-mail cpp@aip.org. }
$$ 